\title{
The Effect of Distance Teaching Experiences on Educators' Attitudes toward Distance Education for Preschoolers
}

\author{
Alexander Veraksa ${ }^{1,2, *}$, Apollinaria Chursina ${ }^{1,2}(\mathbb{D}$ and Margarita Gavrilova 2 (D) \\ 1 Psychological Institute of the Russian Academy of Education, 125009 Moscow, Russia; avchurs@gmail.com \\ 2 Department of Educational Psychology and Pedagogy, Faculty of Psychology, Lomonosov Moscow State \\ University, 125009 Moscow, Russia; gavrilovamrg@gmail.com \\ * Correspondence: veraksa@yandex.ru
}

Citation: Veraksa, A.; Chursina, A.; Gavrilova, M. The Effect of Distance Teaching Experiences on Educators' Attitudes toward Distance Education for Preschoolers. Educ. Sci. 2021, 11, 650. https://doi.org/10.3390/ educsci11100650

Academic Editor: Neil Gordon

Received: 7 September 2021

Accepted: 14 October 2021

Published: 18 October 2021

Publisher's Note: MDPI stays neutral with regard to jurisdictional claims in published maps and institutional affiliations.

Copyright: (c) 2021 by the authors. Licensee MDPI, Basel, Switzerland. This article is an open access article distributed under the terms and conditions of the Creative Commons Attribution (CC BY) license (https:/ / creativecommons.org/licenses/by/ $4.0 /)$.

\begin{abstract}
The aim of the study was to explore and highlight the challenges and benefits of distance education that educators found in their practice of online teaching with preschool children during the first wave of the pandemic. An electronic questionnaire was used to collect teachers' perceptions of (1) their own success in facilitating online sessions; (2) attitudes towards online sessions among teachers with and without experience; (3) factors that, according to teachers with and without experience, determine the effectiveness of online sessions; (4) effectiveness of online sessions for individual mental development goals among teachers with and without such experience. A total of 623 educators participated in the study. Online sessions were of particular benefit to educators who had experience of working remotely with preschool children during the first wave of the pandemic. The results of this study indicate that the capacity of the children and the effectiveness of the online sessions themselves exceeded teachers' expectations in many ways.
\end{abstract}

Keywords: preschool educators; distance education; distance teaching experiences; pedagogical attitudes; pedagogical beliefs

\section{Introduction \\ 1.1. Distance Education Context}

Discussions about distance and online education have always been held in opposition of this form of training to traditional face-to-face education. At different stages of the educational process, this opposition takes on different shades, since the peculiarities of learning at each separate stage are taken into account, as well as the age-related psychological characteristics of the students. This consideration of the problem in the mainstream of the cultural-historical approach and the theory of activity leads us to the idea of preschool age as a stage where active cognitive and emotional development takes place in the course of direct communication with peers and role play [1]. The main social context, where the development process unfolds, are, in addition to peers, a close and social adult. Within the framework of traditional education, a social adult, that is, the teacher, performs certain functions of planning, monitoring, and facilitating group processes in the classroom.

The emergence and spread of the coronavirus pandemic in 2020 contributed to the accelerated restructuring of the educational process. Distance and online learning practices have been introduced around the world and at all levels, and their effects are still in the process of being evaluated. If at the higher education level, these practices were already relatively common, and, therefore, there are numerous studies on the issues of online education in higher education during a pandemic within individual professions [2-5]. In addition, in the case of working with adult students, the assessment of the effectiveness of learning is facilitated by debriefing sessions, as well as detailed discussions, which is difficult when working with children, especially if the ratio of children to one teacher is high. 
However, when considering other levels of education, with each previous level, the experience gained so far is less and less. The experience of distance and online classes for preschool children before the pandemic was extremely small, and, thus, the more valuable is the opportunity to analyze the experience of preschool teachers accumulated during the lockdown [6]. In this case, we nevertheless consider the current educational context as the context of emergency remote teaching, since at present we are talking about a crisis situation of the forced transition of the educational process from traditional face-to-face education to distance learning. In addition, the temporary nature of such a measure within the framework of the current lockdown is emphasized. It is fundamentally important that in the case of online learning we mean a certain system design, it includes various online learning design characteristics (e.g., modality, pacing, roles of the student and teacher, source of feedback, etc.). Emergency remote teaching as a temporary switch in the educational process requires special support from the educational institution to ensure the flexibility of learning, in particular, with regard to the assessment of the context, input, process, and product in the learning process. Furthermore, as a part of remote teaching, which has as an objective the recreation of traditional classroom patterns, emergency remote teaching provides the information to improve current educational practices. Evaluation of the unique experience of preschool educational institutions in an attempt to recreate the educational environment will give us the opportunity to modify and build a coherent practice of remote teaching in preschool education and make it commonplace in world practice $[7,8]$.

\subsection{Distance Education in Preschoolers}

The experience of different countries in distance preschool education showed that the degree of restrictive measures was different: from the complete closure of preschool institutions to their normal functioning, the option of functioning of preschool institutions for essential workers' children was also widespread [9]. In addition, the forms of implementation of online classes with preschool children were also different. Preschool teachers taught thematic zoom classes with children, used instant messengers to share content created by children and parents, created groups on social networks, and more $[10,11]$. The experience of transition to emergency remote teaching in Portugal suggests that preschool teachers, despite seeing such experience as opportunities for the development of educational practice, identified work overload, lack of digital competence, and lack of guidance in matters of restructuring education as important factors. Educators have also noted a decline in student motivation during online classes [12].

In this context, the assistance of parents to the educational process was a necessary part of it, but it must be emphasized that such an experience was difficult for them, since there was a lack of specific recommendations for the implementation of educational activities with a child at home. Furthermore, many parents felt overwhelmed as they continued their work activities, the family care routine, and also had to be actively involved in providing online educational activities for their children. Such an unprecedented experience was reflected in the psychological well-being of the parents [13-16]. A study in Turkey from a parental perspective on the online learning experience of their children during the pandemic showed that the degree of facilitation and even parental participation in the classroom is related to the ages of the children, and that such involvement is necessary in preschool age. The importance of social and emotional support of students from educational institutions was also noted, since such a non-trivial context contributed to social isolation. The importance of self-regulation as a pre-requisite for this form of education is separately highlighted [17].

The context of digitalization of the educational process is an additional factor in the practice of online classes with children. The digitalization of education in many countries is a national initiative, but the real experience of preschool educators is different, which echoes the situation around the world. This problem is associated with various factors, including the lack of professional competencies of teachers [18], the material support 
of the kindergarten [19], teachers' beliefs about the appropriateness ICT in classes with preschool children, personal characteristics of teachers [20], and ideas about the possibility of developing individual mental functions in this way. Research highlights educators' perceptions of the potential of modern technology to develop cognitive and academic skills, but social and emotional skills are left behind.

\subsection{Pedagogical Beliefs towards Distance Education}

Since it is the teachers and educators that are the agents of the implementation of the practice of online classes with preschool children, the investigation of their ideas about such practice is necessary. Positive attitudes regarding the use of ICT in pedagogical practice determine the actual use [21].

Educators' beliefs about the use of ICTs in early childhood education practice have also been explored in conjunction with general pedagogical beliefs that can be described in terms of teacher-centered and student-centered dimensions [22]. It emphasizes not only the goals of education in the preschool period in general, but also the means of achieving these purposes, which is the ratio of general pedagogical beliefs and ICT-related beliefs. It is the development of social skills that is the goal of preschool education in general, but only a few teachers note the possibility of facilitating situations of interaction between children with the ICT. However, educators highlight the potential of ICT both for improving the educational process and prepare children to the primary school education [23].

The ideas and beliefs of teachers regarding the implementation of modern practices with technologies in preschool and school education correlate with their meaningful use, and this, in turn, corresponds to pedagogical, technological, and content knowledge [24]. Various types of teachers' attitudes regarding the use of technology in working with children correlate with each other, while more positive beliefs are related to educational and technological dimensions, that is, obtaining a positive experience of using ICT in educational practice; studying successful examples contribute to the development of educators' ideas about their own self-efficacy in teaching with modern digital technologies [25].

\subsection{The Current Research Objectives}

The accelerated development of online learning in preschool education contributed to the emergence of new methods and strategies of teaching and learning, which required consolidated efforts from both teachers and parents $[26,27]$. The digital socialization of the child [28], which is already unfolding everywhere as a new normality, consequently acquired new shades during the pandemic, which requires an evaluation of the learning and teaching process, since the teacher is still a bearer of cultural norms and forms of interaction [1]. The purpose of our study was to assess the beliefs of educators in public preschool educational institutions regarding the practice of online classes with children, depending on various possible criteria for their effectiveness and the presence of such experience. Our aim was to find what determines the attitude to distance education, and, furthermore, the potential practical application in working with teachers on the positive attitudes to distance and online education as one of the means of teaching and, in general, as an adaptation to the new normality.

\section{Materials and Methods}

The study involved 623 preschool educators of public kindergartens. Of these, $26 \%$ of respondents had online teaching experience with preschoolers during the first wave of the COVID-19 pandemic (March-July 2020). The average teaching experience of the respondents was about 17 years $(M=17.31, S D=6.42)$. The gender specificity of the study sample should be especially noted. All the respondents were women.

The data collection process implied distribution of an online form created on a specialized platform "Testograf" (see Appendix A). Preschool educators who work with children between the ages of 3 and 7 were invited to participate in the study through preschool 
institutions of higher education, kindergarten, and school management, and specialized professional preschool teachers' communities.

An online questionnaire was used as the main research method. This questionnaire is an author's instrument, which consists of four main topic sections:

1. Evaluation of the teacher's own success in conducting online classes;

2. Characteristics of online classes for preschoolers (pros and cons);

3. Factors affecting the effectiveness of online classes for preschoolers;

4. Effectiveness of online classes for individual lines of children mental development.

This questionnaire structure was built on the basis of scientific research on the problems of online learning $[29,30]$ and was compiled using the Likert scale. Depending on the topic section, the study participants had to answer from 11 to 20 questions. A total of 60 statements were presented, in order that the educators gave their answer according to the level of agreement with them on a 5-point Likert scale: from 1 ("Strongly disagree") to 5 ("Strongly agree").

Therefore, various research questions were defined for this study:

1. Does the teachers' auto-evaluation in conducting online classes depend on the experience in conducting such classes?

2. Is there a difference between preschool educators in online classes perception as a mean of educational process?

3. Are there any factors determining the effectiveness of online classes for educators with online teaching experience in comparison to teacher with no such experience?

4. Which individual lines of mental development are considered to be potentially developed in online classes?

The study results were processed both for the entire sample and separately for two main groups into which the entire sample was divided: teachers with experience in conducting online classes during the COVID-19 pandemic (26\%) and teachers without such experience $(74 \%)$. The analysis of the entire data set was carried out using the special Jamovi software version 1.0.7.0 (Jamovi project). At the first stage of data processing, confirmatory factor analysis (principal axis factoring extraction method was used in combination with oblimin rotation) was used to determine the structure of the obtained data. At the second stage, a one-way ANOVA was carried out to study the modality of teachers' beliefs about online classes, taking into account their experience in conducting online classes with preschool children.

\section{Results}

\subsection{Factor Analyses}

Based on the results of factor analysis, four main factors were identified, which describe $51.4 \%$ of the variance (significance level $>0.5$, Table 1 ).

The resulting factor structure confirms the four-component theoretical model, which formed the basis for the study questionnaire. The most significant factor in relation to online classes for educators was "evaluation of the teacher's own success in conducting online classes". Positively reinforced experience significantly affects positive attitudes towards the effectiveness of online classes. 
Table 1. Factor analysis.

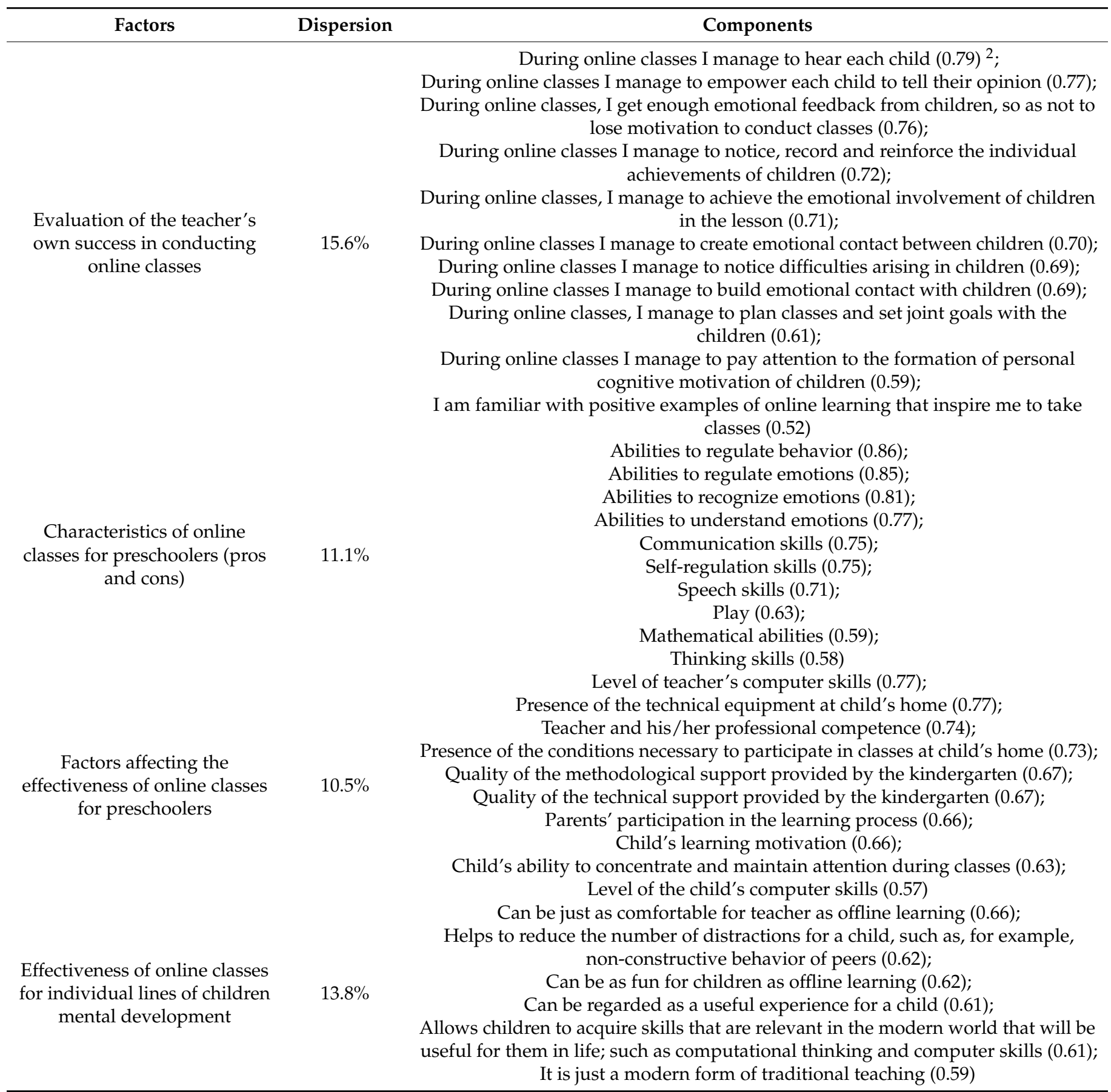

Bartlett's Test of Sphericity $\left(\chi^{2}=6459, \mathrm{df}=1770, p<0.001\right) .{ }^{2}$ Correlation coefficients between a variable and a specific factor.

\subsection{One-Way ANOVA}

According to the results of the second stage of data processing using the analysis of variance, significant differences were found for a group of teachers with experience in conducting online classes during the first wave of the pandemic and a group of teachers without such experience (Table 2). 
Table 2. ANOVA.

\begin{tabular}{|c|c|c|c|c|c|}
\hline $\begin{array}{c}\mathrm{N}^{\circ} \\
\text { Factor }\end{array}$ & Representation to Online Lessons & Group Descriptives & Mean & SD & SE \\
\hline \multirow{2}{*}{4} & \multirow{2}{*}{ it is just a modern form of traditional teaching } & have experience & 2.99 & 1.247 & 0.1021 \\
\hline & & no experience & 2.76 & 1.236 & 0.0568 \\
\hline 4 & more comfortable form of teaching than offline training from the organizational point of view & no experience & 2.15 & 1.106 & 0.0508 \\
\hline \multirow{2}{*}{4} & \multirow{2}{*}{ has a high degree of clarity of the demonstrated materials } & have experience & 2.81 & 1.201 & 0.0984 \\
\hline & & no experience & 2.77 & 1.177 & 0.0541 \\
\hline 4 & allows to increase the size of the group & have experience & 2.82 & 1.220 & 0.0999 \\
\hline \multirow[b]{2}{*}{4} & \multirow{2}{*}{ can be regarded as a rewarding experience for the child } & have experience & 3.19 & 1.153 & 0.0945 \\
\hline & & no experience & 2.92 & 1.175 & 0.0540 \\
\hline \multirow[b]{2}{*}{4} & allows children to acquire skills that are relevant in the modern world that will be useful for & have experience & 3.31 & 1.150 & 0.0942 \\
\hline & them in life, such as computational thinking and computer skills & no experience & 3.22 & 1.100 & 0.0505 \\
\hline \multirow[b]{2}{*}{4} & helps to reduce the number of distractions for a child, such as, for example, non-constructive & have experience & 2.88 & 1.133 & 0.0928 \\
\hline & behavior of peers & no experience & 2.81 & 1.136 & 0.0522 \\
\hline \multirow[b]{2}{*}{4} & \multirow{2}{*}{ can be as fun for children as offline learning } & have experience & 3.21 & 1.050 & 0.0860 \\
\hline & & no experience & 2.99 & 1.155 & 0.0530 \\
\hline 4 & can be just as comfortable for teacher as offline learning & have experience & 2.84 & 1.145 & 0.0938 \\
\hline \multirow{2}{*}{4} & \multirow{2}{*}{ associated with higher fatigue in children than offline learning } & have experience & 3.50 & 1.082 & 0.0886 \\
\hline & & no experience & 3.38 & 1.180 & 0.0542 \\
\hline \multirow{2}{*}{4} & \multirow{2}{*}{ associated with higher fatigue in teacher than offline learning } & have experience & 3.45 & 1.105 & 0.0906 \\
\hline & & no experience & 3.38 & 1.122 & 0.0515 \\
\hline \multirow[b]{2}{*}{4} & \multirow{2}{*}{ reduces the authority of the teacher in the eyes of children } & have experience & 2.60 & 1.150 & 0.0942 \\
\hline & & no experience & 3.07 & 1.206 & 0.0554 \\
\hline \multirow[b]{2}{*}{4} & \multirow{2}{*}{ provides a low memorization of the material in comparison with offline teaching } & have experience & 3.07 & 1.143 & 0.0936 \\
\hline & & no experience & 3.34 & 1.114 & 0.0512 \\
\hline \multirow{2}{*}{4} & \multirow{2}{*}{ cannot replace offline learning for preschool children } & have experience & 4.16 & 1.121 & 0.0919 \\
\hline & & no experience & 4.14 & 1.133 & 0.0521 \\
\hline \multirow{2}{*}{4} & \multirow{2}{*}{ not as deep as offline learning } & have experience & 3.85 & 1.095 & 0.0897 \\
\hline & & no experience & 3.96 & 1.063 & 0.0488 \\
\hline \multirow{2}{*}{4} & \multirow{2}{*}{ will never replace the developmental potential of offline learning } & have experience & 4.11 & 0.974 & 0.0798 \\
\hline & & no experience & 4.15 & 1.038 & 0.0477 \\
\hline
\end{tabular}


Table 2. Cont.

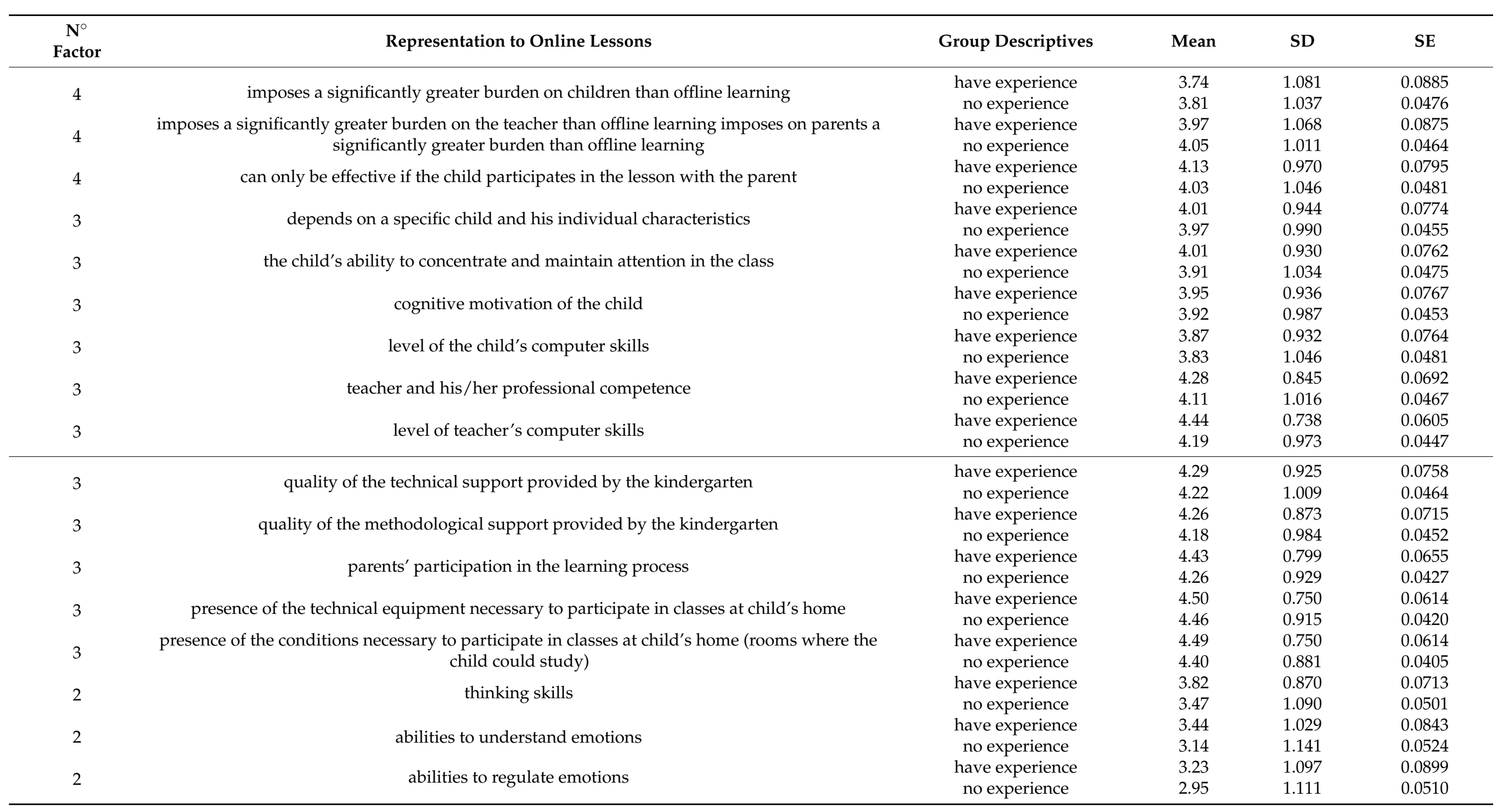


Table 2. Cont.

\begin{tabular}{|c|c|c|c|c|c|}
\hline $\begin{array}{l}\mathbf{N}^{\circ} \\
\text { Factor }\end{array}$ & Representation to Online Lessons & Group Descriptives & Mean & SD & SE \\
\hline \multirow{2}{*}{2} & \multirow{2}{*}{ abilities to regulate behavior } & have experience & 3.13 & 1.119 & 0.0917 \\
\hline & & no experience & 2.81 & 1.117 & 0.0513 \\
\hline 2 & abilities to recognize emotions & no experience & 3.03 & 1.142 & 0.0524 \\
\hline \multirow[b]{2}{*}{2} & \multirow[b]{2}{*}{ communicative skills } & have experience & 3.14 & 1.219 & 0.0999 \\
\hline & & no experience & 2.77 & 1.182 & 0.0543 \\
\hline 2 & self-regulation skills & have experience & 3.17 & 1.125 & 0.0922 \\
\hline \multirow{2}{*}{2} & \multirow{2}{*}{ mathematical abilities } & have experience & 3.69 & 0.892 & 0.0731 \\
\hline & & no experience & 3.38 & 1.084 & 0.0498 \\
\hline \multirow{2}{*}{2} & \multirow{2}{*}{ speech skills } & have experience & 3.36 & 1.091 & 0.0894 \\
\hline & & no experience & 2.91 & 1.183 & 0.0544 \\
\hline \multirow{2}{*}{2} & \multirow{2}{*}{ play } & have experience & 3.28 & 1.229 & 0.1007 \\
\hline & & no experience & 2.90 & 1.215 & 0.0558 \\
\hline
\end{tabular}


The data on the questions (Table 2) for the two selected groups make it possible to highlight significant differences in the mean point values. For each statement, the mean values are significantly higher for a group of teachers with experience in conducting online classes during the first wave of the pandemic. Only seven cases demonstrated higher mean values for the group of teachers without experience in conducting online classes. All these cases were associated with a higher evaluation of characteristics that demonstrate negative parameters of online learning ("reduces the authority of the teacher in the eyes of children"; "provides low memorization of the material in comparison with offline learning"; "not as deep as offline learning"; "never replaces the developmental potential of offline learning"; "imposes a significantly greater burden on children than offline learning"; "imposes a significantly greater burden on the teacher than offline learning, imposes a significantly greater burden on parents than offline learning").

The tendency to point out positive external and internal factors that can affect the effectiveness of online classes is largely correlated with the success of the personal experience of teachers who had experience in conducting online classes with preschoolers during the first wave of the COVID-19 pandemic.

\section{Discussion}

The purpose of this study was to evaluate the attitudes of preschool teachers to online classes. We examined various aspects of such perceptions of educators, in particular, we touched upon ideas about assessing a teacher's own success in conducting online classes, characteristics of online classes for preschoolers (pros and cons), factors affecting the effectiveness of online classes for preschoolers and effectiveness of online classes for individual lines of mental development of children. This is the first time that educational institutions in most countries of the world have been completely closed and switched to the format of remote work. Teachers and educators around the world have undergone dramatic changes in working conditions and were forced to master new forms of teaching for contact and social support for children and their families during the period of confinement. The factors that ensure the resilience of preschool teachers to social changes in working conditions in connection with the COVID-19 pandemic and determine the degree of teachers' satisfaction with their own work remotely were analyzed.

The forced transition to emergency remote teaching made it possible to accumulate new experience in the field of preschool education. Online teaching experience is associated with pedagogical attitudes regarding such experience in general. Significant differences were found in attitudes towards online classes for preschoolers among educators who already have experience in this format and those who do not yet. Educators with online teaching experience are much more positive about it than their colleagues without such experience. Educators with experience in teaching online classes are more likely to believe that online classes can be useful, fun, and comfortable for the child, and that such classes provide memorization comparable to offline learning. Our results are consistent with previous studies, since, within the framework of various theoretical models, it was shown that practice with ICT, gaining experience of interacting with them, studying working examples and gaining experience are sources for positive self-beliefs in using technologies for teachers [25].

Despite the different nature of the negative educators' attitudes regarding technologies in preschool education, it is important to consider the possibilities of individual teaching and learning tools in depth, since their potential for the development of a child and his/her psyche is different. At the same time, it is extremely important for the development of new competencies in children that they could gain their own experience in an active form of interaction, and not through imitation of the teacher or knowledge retransmission [31].

Remote teaching was initially designed and considered as the possibility to recreate traditional learning environment in the new modality. This is precisely what correlates with the ability to maintain active interaction between teacher and student, as well as to 
diversify its forms. Teachers with experience in conducting online classes, in our study, are more disposed to believe that the effectiveness of such classes depends on them and their level of professional training, computer skills, as well as on the participation of parents in the learning process. Indeed, teachers note the need to create general recommendations for the implementation of modern technologies in the practice of preschool education, since there is no broad empirical base or widespread practice of profile training for teachers in the field of online classes and digital devices [32,33].

The preschool age is distinguished by the importance of various layers of social interaction, and this applies to parents, teachers, and peers. The need to obtain different experiences in interaction is due to the active development of mental functions. Preschool teachers with experience in conducting online classes are significantly more inclined to believe that an online class can be structured in such a way that it will contribute to the development of play, thinking, mathematical, communication, and speech abilities in children, as well as the ability to recognize, understand, and regulate emotions. For example, the practice of Swedish kindergarten teachers [34] is consistent with our results, as they highlighted the potential of modern technology to promote various lines of mental development, including speech, mathematical ability, critical thinking, and others.

As a limitation of our study, we would like to note that it is rather exploratory. It was attended by 623 preschool teachers, and only $26 \%$ of them had experience in conducting online classes during the coronavirus pandemic. Such a relatively low percentage of those who have mastered distance learning with preschool children can be explained by various factors. On the one hand, despite the fact that the digitalization of the educational process at all levels is a national initiative, the real situation in the country is rather heterogeneous. It is noted that there are differences in the technical support of kindergartens depending on the region, as well as the fact that there is no general methodology for conducting such classes. It is not enough just to transfer to online those activities that are familiar and routine for lessons with preschoolers; the curriculum needs to be reframed for a new format of tasks. Furthermore, as it was repeatedly noted earlier, in many studies, teachers noted both the need for appropriate training in technical skills, and the lack of recommendations for the effective design and realization of such classes. We would also like to emphasize that our study used a questionnaire, while in order to better understand the nature and process of online learning, and most importantly, the real pedagogical beliefs behind it, it is necessary to complement and enrich the study with in-depth interviews with educators. Furthermore, for a deeper and more differentiated understanding of the attitude towards ICT and online classes with children and the real practice of their implementation, it is necessary to compare the views of teachers with the parents' attitudes. Preschool and primary school teachers are generally more positive than parents about ICT and online learning, although they all have constructive and optimistic attitudes in this sense [29]. Features of the use of electronic devices and technology in classroom and at home are different in childhood, which potentially explains the statistically significant differences in attitudes of caregivers and parents. In addition, there is a different impact of the use of electronic devices by children on cognitive, emotional, and social development, with both short- and long-term effects and development outcomes [35]. These factors are traditionally considered as the ones that underlie the parents' attitudes regarding online education and digital devices. These parents' concerns only intensified during the quarantine, since the usual mode of activity of children was disrupted [36].

However, in the case of preschool education, it is the common teamwork of teachers and parents that determines effective classes with children, since self-regulation skills are not yet formed, which means that activities control and planning during the lesson should be external. Preschool educators note the positive effects of technology in the classroom, for example, visibility and facilitation of material delivery, their usefulness and support for motivation in children [29]. Therefore, we will be able to generalize the experience that already exists at the moment, assimilate it and build on its basis methodological recommendations and frameworks for educators and parents of preschool children. 


\section{Conclusions}

In our country and around the world, starting from March 2020, in order to minimize the risks of the spread of a new coronavirus infection, preschool educational institutions, schools, and universities were transferred to the remote online education mode. Against the background of frequent changes in the epidemiological situation all over the world, it is still necessary to study the features of the educational process during a pandemic, in particular, using distance learning [9]. More effective policies to combat the spread of the disease and maintain the quality of the educational process may be developed when these characteristics are analyzed and assimilated [37,38]. Today, the least studied education level in the ongoing pandemic is preschool education, and its online transition is still being discussed [39]. The scientific community around the world has consolidated for the transition to the format of distance education, development and assessment of the current characteristics of the transition of the educational process, design of methodological recommendations. This is a rare case when theory and practice develop together. Online classes were considered by both educators and parents as a necessary measure, as opposed to their absence during the confinement. At the same time, the particular benefit of online classes was noted by those preschool teachers who, during the first wave of the pandemic, had experience working with preschoolers in an online mode. The results of our study indicate that the capabilities of children and the effectiveness of online classes themselves have largely exceeded the expectations of educators. The online environment allows, with a competent approach, to develop certain higher mental functions in preschool children. The transfer of traditional educational activities to a distant form, according to teachers' evaluation, depends on various factors related to their own professional training and the design of these classes.

Author Contributions: Conceptualization, A.V.; data curation, M.G.; formal analysis, A.C.; funding acquisition, A.V.; investigation, A.C.; methodology, A.V., A.C. and M.G.; project administration, A.V.; resources, M.G.; software, M.G.; supervision, A.V.; validation, A.C. and M.G.; visualization, M.G.; writing—original draft, A.C.; writing-review \& editing, A.V. All authors have read and agreed to the published version of the manuscript.

Funding: This research was funded by Grant of the President of the Russian Federation for State Support of Young Russian Scientists and for State Support of Leading Scientific Schools of the Russian Federation, grant number МД-6168.2021.2.

Institutional Review Board Statement: The study and consent procedures were approved by the Ethics Committee of Faculty of Psychology at Lomonosov Moscow State University (the approval No: 2021/68).

Informed Consent Statement: Informed consent was obtained from all subjects involved in the study.

Data Availability Statement: The full data set is available upon request to the corresponding author.

Conflicts of Interest: The authors declare no conflict of interest.

\section{Appendix A}

Questionnaire items

I believe that it is possible to structure an online learning in such a way that it promotes of the ability to regulate their behavior

I believe that it is possible to structure an online learning in such a way that it promotes of the ability to recognize emotions

I believe that it is possible to structure an online learning in such a way that it promotes of the communicative skills

I believe that it is possible to structure an online learning in such a way that it promotes of the ability to understand emotions

I believe that it is possible to structure an online learning in such a way that it promotes of the ability to regulate their emotions 
I believe that it is possible to structure an online learning in such a way that it promotes of the self-regulation skills

I believe that it is possible to structure an online learning in such a way that it promotes of the speech skills

I believe that it is possible to structure an online learning in such a way that it promotes of socio-dramatic play

I believe that it is possible to structure an online learning in such a way that it promotes the development of pre-school children's thinking skills

I believe that it is possible to structure an online learning in such a way that it promotes of the mathematical abilities

Online learning can be regarded as a useful experience for a child

Online learning allows children to get the skills that are relevant in the modern world and will be useful to them in life

Online learning is simply a modern form of traditional learning

Online learning allows for higher visibility of visual materials

Online learning can be just as engaging for children as offline learning

Online learning can be just as comfortable for a teacher as offline learning

Effectiveness of online learning depends on the level of teacher's computer skills

Effectiveness of online learning depends on the teacher and her or his professional competence

Effectiveness of online learning depends on the quality of methodological support provided by the kindergarten

Effectiveness of online learning depends on the quality of technical support provided by the kindergarten

Effectiveness of online learning depends on the parent participation in the learning process

Effectiveness of online learning depends on the child's learning motivation

Effectiveness of online learning depends on the child's ability to concentrate and maintain attention during classes

Effectiveness of online learning depends on the level of a child's computer skills

I believe that the effectiveness of online learning for pre-school children depends on the specific child and his or her individual characteristics

Online learning can only be effective if the child participates in the class together with the parent

Online learning cannot replace offline learning for preschool children

Online learning will never replace the developmental potential of offline learning

Online learning is not as deep as offline learning

Online learning significantly increases the workload on children compared to offline learning

Online learning provides low memorability of the material taught compared to offline training

Online learning significantly increases the workload on educators compared to offline learning

Online learning is associated with higher fatigue in educators than offline learning

Online learning reduces the teacher's authority in the children's eyes

In my online classes, I manage to pay attention to the formation of children's personal learning motivation

In my online classes, I manage to plan classes together with the children and to set common goals

In my online classes, I am able to notice, register and bolster the individual achievements of the children

In my online classes, I manage to build emotional contact with the children

In my online classes, I manage to create emotional contact between the children

In my online classes, I manage to ensure the children's emotion 
In my online classes, I get enough emotional feedback from children so that I don't lose motivation to conduct the class

In my online classes my online classes I get to hear every child

In my online classes I am able to notice the difficulties that may arise for the children In my online classes I manage to give every child the opportunity to express their opinion

In my online classes I discuss with children both the negative and positive emotions that arise in the process

In my online classes I know how to counteract online bullying among children in my online classes

In my online classes the children's attitude to online learning is largely determined by the attitude of the adults (educators and parents)

In my online classes I am familiar with positive examples of online learning that inspire me

In my online classes I feel a lack of knowledge and skills needed to successfully conduct online classes

\section{References}

1. Vygotsky, L.S. Mind in Society: The Development of Higher Psychological Processes; Cole, M., John-Steiner, V., Scribner, S., Eds.; Harvard University Press: Cambridge, MA, USA, 1978.

2. de Boer, H. COVID-19 in Dutch Higher Education. Studies in Higher Education. 2020, 46, 96-106. [CrossRef]

3. Yang, R. China's higher education during the COVID-19 pandemic: Some preliminary observations. High. Educ. Res. Dev. 2020, 39, 1317-1321. [CrossRef]

4. Said-Hung, E.; Garzón-Clemente, R.; Marcano, B. Ibero-American higher education institutions facing COVID-19. J. Hum. Behav. Soc. Environ. 2020, 31, 497-511. [CrossRef]

5. Lewis, E.E.; Taylor, L.J.; Hermsen, J.L.; McCarthy, D.P.; Fiedler, A.G. Cardiothoracic Education in the Time of COVID-19: How I Teach It. Ann. Thorac. Surg. 2020, 110, 362-363. [CrossRef] [PubMed]

6. Kim, J. Learning and teaching online during COVID-19: Experiences of student teachers in an early childhood education practicum. Int. J. Early Child. 2020, 52, 145-158. [CrossRef] [PubMed]

7. Hodges, C.; Moore, S.; Lockee, B.; Trust, T.; Bond, A. The Difference between Emergency Remote Teaching and Online Learning. EDUCAUSE Review. 2020. Available online: https://er.educause.edu/articles/2020/3/the-difference-between-emergencyremote-teaching-andonline-learning (accessed on 7 October 2021).

8. Vlachopoulos, D.; Sangra, A.; Cabrera, N. The Conceptual Framework of e-Learning: A View from Inside. Int. J. Learn. Annu. Rev. 2012, 18, 93-104. [CrossRef]

9. Samuelsson, I.P.; Wagner, J.T.; Ødegaard, E.E. The coronavirus pandemic and lessons learned in Preschools in Norway, Sweden and the United States: OMEP policy forum. Int. J. Early Child. 2020, 52, 129-144. [CrossRef] [PubMed]

10. Tokić, I.S.; Vukašinović, A. Continuity of Educational Process through Virtual Kindergarten during Covid-19 Outbreak-Case Study from Croatia. In Proceedings of the 12th Annual International Conference on Education and New Learning Technologies, Palma, Spain, 6-8 July 2020. [CrossRef]

11. Szente, J. Live Virtual Sessions with Toddlers and Preschoolers Amid COVID-19: Implications for Early Childhood Teacher Education. J. Technol. Teach. Educ. 2020, 28, 373-380. Available online: https://www.learntechlib.org/primary/p/216174/ (accessed on 10 August 2021).

12. Seabra, F.; Teixeira, A.; Abelha, M.; Aires, L. Emergency remote teaching and learning in Portugal: Preschool to secondary school Teachers' perceptions. Educ. Sci. 2021, 11,349. [CrossRef]

13. Waters, L.H.; Leong, P. Who is teaching? New roles for teachers and parents in cyber charter schools. J. Technol. Teach. Educ. 2014, 22, 33-56. Available online: https:/ / www.learntechlib.org/primary/p/112373// (accessed on 10 August 2021).

14. Listyaningrum, R.A.; Sari, M.W.N.N.; Yuniar, D.P. Analysis of the Needs of Parents in Mentoring Early Childhood During Learning from Home. In Proceedings of the 2nd Early Childhood and Primary Childhood Education (ECPE 2020); Atlantis Press: Paris, France, 2020; pp. 223-229. [CrossRef]

15. Dong, C.; Cao, S.; Li, H. Young Children's Online Learning during COVID-19 Pandemic: Chinese Parents' Beliefs and Attitudes. Child. Youth Serv. Rev. 2020, 118, 105440. [CrossRef] [PubMed]

16. Zinchenko, Y.P.; Morosanova, V.I.; Kondratyuk, N.G.; Fomina, T.G. Conscious Self-Regulation and Self-organization of Life during the COVID-19 Pandemic. Psychol. Russ. State Art 2020, 13, 168-182. [CrossRef]

17. Lopez-Belmonte, J.; Pozo-Sanchez, S.; Fuentes-Cabrera, A.; Trujillo-Torres, J.-M. Analytical competences of teachers in big data in the era of digitalized learning. Educ. Sci. 2019, 9, 177. [CrossRef]

18. Misirli, O.; Ergulec, F. Emergency remote teaching during the COVID-19 pandemic: Parents experiences and perspectives. Educ. Inf. Technol. 2021. [CrossRef] [PubMed] 
19. Carver, L.; Todd, C. Teacher perception of barriers and benefits in K-12 technology usage. In Proceedings of the 10th International Technology, Education and Development Conference, Valencia, Spain, 7-9 March 2016. [CrossRef]

20. Hinojo-Lucena, F.J.; Aznar-Díaz, I.; Caceres-Reche, M.P.; Trujillo-Torres, J.M.; Romero-Rodríguez, J.M. Factors influencing the development of digital competence in teachers: Analysis of the teaching staff of permanent education centres. IEEE Access 2019, 7, 178744-178752. [CrossRef]

21. Tsuei, M.; Hsu, Y.Y. Parents' acceptance of participation in the integration of technology into children's instruction. Asia-Pac. Educ. Res. 2019, 28, 457-467. [CrossRef]

22. Ertmer, P.A.; Ottenbreit-Leftwich, A.T.; Tondeur, J. Teachers' Beliefs and Uses of Technology to Support 21st-Century Teaching and Learning. In International Handbook of Research on Teacher Beliefs; Fives, H., Gill, M.G., Eds.; Routledge: Oxford, UK, 2014; pp. 1239-1262.

23. Mertala, P. Wag the dog-The nature and foundations of preschool educators' positive ICT pedagogical beliefs. Comput. Hum. Behav. 2017, 69, 197-206. [CrossRef]

24. Koehler, M.J.; Mishra, P.; Kereluik, K.; Shin, T.S.; Graham, C.R. The Technological Pedagogical Content Knowledge Framework. In Handbook of Research on Educational Communications and Technology; Spector, M.J., Merrill, D.M., Elen, J., Bishop, J.M., Eds.; Springer: New York, NY, USA, 2014; pp. 101-111.

25. Scherer, R.; Tondeur, J.; Siddiq, F.; Baran, E. The importance of attitudes toward technology for pre-service teachers' technological, pedagogical, and content knowledge: Comparing structural equation modeling approaches. Comput. Hum. Behav. 2018, 80, 67-80. [CrossRef]

26. Baranova, V.A.; Dubovskaya, E.M.; Savina, O.O. Educational environment amid COVID-19 pandemic: New security challenges. Natl. Psychol. J. 2020, 13, 57-65. (In Russian) [CrossRef]

27. Leonova, E.V. Parents and children in time of isolation: External and internal factors of mutual understanding. Natl. Psychol. J. 2020, 13, 48-56. (In Russian) [CrossRef]

28. Soldatova, G.U.; Rasskazova, E.I.; Chigarkova, S.V. Digital Socialization of Adolescents in the Russian Federation: Parental Mediation, Online Risks, and Digital Competence. Psychol. Russ. State Art 2020, 13, 191-206. [CrossRef]

29. Ramírez-Rueda, M.C.; Cózar-Gutiérrez, R.; Colmenero, M.J.R.; González-Calero, J.A. Towards a coordinated vision of ICT in education: A comparative analysis of Preschool and Primary Education teachers' and parents' perceptions. Teach. Teach. Educ. 2021, 100, 103300. [CrossRef]

30. Baş, G.; Kubiatko, M.; Sünbül, A.M. Teachers' perceptions towards ICTs in teaching-learning process: Scale validity and reliability study. Comput. Hum. Behav. 2016, 61, 176-185. [CrossRef]

31. Dong, C.; Mertala, P. It is a tool, but not a 'must': Early childhood preservice teachers' perceptions of ICT and its affordances. Early Years 2019. [CrossRef]

32. Kamaruddin, K.; Abdullah, C.A.C.; Idris, M.N.; Nawi, M.N.M. Teachers' Level of ICT Integration in Teaching and Learning: A Survey in Malaysian Private Preschool. AIP Conf. Proc. 2017, 1891, 020075. [CrossRef]

33. Dong, C.; Newman, L. Ready, steady ... pause: Integrating ICT into Shanghai preschools. Int. J. Early Years Educ. 2016, 24, 224-237. [CrossRef]

34. Otterborn, A.; Schönborn, K.; Hultén, M. Surveying preschool teachers' use of digital tablets: General and technology education related findings. Int. J. Technol. Des. Educ. 2019, 29, 717-737. [CrossRef]

35. Kostyrka-Allchorne, K.; Cooper, N.R.; Simpson, A. The relationship between television exposure and children's cognition and behaviour: A systematic review. Dev. Rev. 2017, 44, 19-58. [CrossRef]

36. Orgilés, M.; Morales, A.; Delvecchio, E.; Mazzeschi, C.; Espada, J.P. Immediate Psychological Effects of the COVID-19 Quarantine in Youth From Italy and Spain. Front. Psychol. 2020, 11, 2986. [CrossRef] [PubMed]

37. Reimers, F.M.; Schleicher, A. A Framework to Guide an Education Response to the COVID-19 Pandemic of 2020; OECD: Paris, France, 2020.

38. Crawford, J.; Butler-Henderson, K.; Rudolph, J.; Malkawi, B.; Glowatz, M.; Burton, R.; Lam, S. COVID-19: 20 countries' higher education intra-period digital pedagogy responses. J. Appl. Learn. Teach. 2020, 3, 1-20. [CrossRef]

39. Viner, R.M.; Russell, S.J.; Croker, H.; Packer, J.; Ward, J.; Stansfield, C.; Booy, R. School closure and management practices during coronavirus outbreaks including COVID-19: A rapid systematic review. Lancet Child Adolesc. Health. 2020. [CrossRef] 